\title{
City planning and energy efficiency: towards an integrated urban design and planning process
}

\author{
E. Barreiro ${ }^{1}$, J. Belausteguigoitia ${ }^{1}$, E. Perea ${ }^{2}$, R. Rodríguez ${ }^{2}$, \\ A. Romero ${ }^{1} \&$ E. Turienzo ${ }^{2}$ \\ ${ }^{1}$ Building and Territorial Development Unit, Labein Tecnalia, Spain \\ ${ }^{2}$ Energy Unit, Labein Tecnalia, Spain
}

\begin{abstract}
Urban environments are great consumers of energy. In Spain, the housingservices sector is responsible for almost $30 \%$ of the total energy consumption. There are many initiatives towards the reduction of energy consumption in buildings. However, many of the alternatives are diminished due to a lack of a holistic approach in the planning, design, and building of new communities. This paper reports a new methodology that integrates concepts of energy efficiency in the overall planning and design process. A community in Toledo, Spain, serves as a case study to extract conclusions later applicable to other areas. The methodology evaluates energy efficiency solutions at different scales and stages within the planning and building process of both neighbourhood and buildings. It then revises the planning and building protocols for the optimization of the community's energy efficiency, contemplating their practical applicability. With this, the proposed integrated methodology is improved and adapted to a widereaching design of energy efficient urban communities.
\end{abstract}

Keywords: city planning, energy efficiency, energy modelling, eco communities, resources management, environmental economics.

\section{Introduction}

Urban environments are great consumers of energy. In Spain, housing and services are responsible for $27 \%$ of the country's total energy consumption (Eurostat [1]). In Europe, this figure mounts to $41 \%$, highlighting the relevance 
of the housing-services sector when compared to industry and transportation, which represent $28 \%$ and $31 \%$, respectively, of the total energy consumption (Eurostat [2]). There are many initiatives towards the reduction of energy consumption in buildings. In Spain, these range from regulations, such as the recent building code (Código Técnico de la Edificación, CTE [3]), to incentives, such as those proposed in the Spanish Energy Efficiency and Saving Action Plan (IDAE [4]), to best practices, such as bioclimatic architecture. However, many of the alternatives are diminished due to a lack of a holistic approach in the planning, design, and building of new communities. In other words, by the time energy efficiency initiatives are applied, much of the community's potential for these has already been missed. The challenge to meet the European energy target of reducing overall energy consumption by $9 \%$ by 2016 (European Parliament [5]), together with the Kyoto Protocol on GHG emissions, unveils a critical need to integrate energy efficiency concepts early on and throughout the planning, design, and building process of new urban communities.

This paper contributes to this notion through an integrated methodology for the design of new urban communities. As a way to extract conclusions later applicable to other areas, the methodology is applied to the design of an energy efficient community in Toledo, Spain. The 46-hectare site is part of ARTE (Architecture and Territory), an initiative of Fundación Metrópoli and Ecocities.

\section{Parameters for the design of energy efficient communities}

In order to define an urban scenario from en energy efficiency point of view, the methodology sets off by compiling key site data relative to the area's topography and geography, climate, planning, and materials and building systems. These affect the two core aspects of an energy efficient community: energy demand and energy generation. Table 1 shows the factors that affect a community's energy efficiency in terms of optimizing its energy demand. For the case study, the analysis of these factors stresses the importance of solar gain and protection through optimal distance between buildings, percentage of glazing according to orientation and building use, and shading elements, among others.

Table 1: $\quad$ Factors that affect the energy efficiency of a community.

\begin{tabular}{|c|c|c|c|}
\hline $\begin{array}{l}\text { Urban } \\
\text { plannning }\end{array}$ & $\begin{array}{l}\text { Regulations } \\
\text { Climate } \\
\text { Land uses }\end{array}$ & $\begin{array}{l}\text { Other urban } \\
\text { elements }\end{array}$ & $\begin{array}{l}\text { Street network } \\
\text { Open spaces }\end{array}$ \\
\hline Building & $\begin{array}{l}\text { Building typology } \\
\text { Parcel } \\
\text { Distance between } \\
\text { buildings } \\
\text { Percentage of glazing } \\
\text { Shading elements }\end{array}$ & $\begin{array}{l}\text { Building } \\
\text { solutions }\end{array}$ & $\begin{array}{l}\text { Façade } \\
\text { Roof } \\
\text { Ground floor slab } \\
\text { Glazing } \\
\text { Vegetation }\end{array}$ \\
\hline
\end{tabular}

As for energy generation and storage, the key parameters to consider are on the one hand, energy generating potential and, on the other, cost-effectiveness, sustainability (GHG emissions), and energy efficiency (energy saving). Applied 
to the case study, this entails a mixed system for energy generation to minimize risk, such as CHP (Combined Heat and Power), solar, and geothermal, given that there is an absence of wind and hydro potential on-site. The dimensioning of the sources for the system to be cost-effective (e.g. through the sale of energy to the grid [6]) must take into account the following considerations: aspects of cost (e.g. equipment, resources, maintenance, etc.), energy generation predictions, climatic data, compilation with regulations (e.g. the Spanish building code, CTE), and the operation agreement following either predictions on renewable resources (e.g. photovoltaic, solar), or predictions on the rest of the thermal load that cannot be supplied by solar and geothermal, through CHP. With this approach, the community will comply with existing regulation according to the equivalent electric output of the CHP, and hence the community will be able to benefit from the energy sale to the corresponding energy facility.

Last, it is important to design an energy management system for the operation of the energy generation. Part of the generation and storage, as well as the load, may be grouped and distributed through an electric and thermal microgrid (Perea et al. $[7,8]$ ), with operation agreements coming from the microgrid operator or from the utility operator, with the consequent economic benefits. In the energy planning and design stages it is also key to specify requisites and spaces, such as leaving space in rooftops as leisure areas (required in the case study), and leave a percentage for unknown future innovations (e.g. biomass as an energy generating vector, and hydrogen or the electric vehicle as storage elements).

\section{Optimization of the community's energy demand}

Following the factors that affect the energy efficiency of a community (Table 1), the integrated methodology develops a set of energy efficiency solutions at different scales and times of the planning-building process, to optimize the community's overall energy demand. These are later evaluated and the optimal ones are integrated in the development of the concept plan for the case study.

\subsection{Solutions in different scales and times of the planning-building process}

\subsubsection{Urban planning}

The analysis of the different urban planning regulations applicable in Spain shows deficiencies for the implantation of wide-reaching energy efficiency solutions at this stage. Within the Spanish urban planning system, the planning figure identified as critical for the design of energy efficient communities is the Plan Parcial (PP), equivalent to a district-scale master plan. The PP establishes aspects such as the open space network, urban fabric (location and geometry of urban blocks), building typologies and dimensional parameters, land uses, basic infrastructures, and development economic cost. Due to the influence of PP-level decisions in the community's capacity for energy efficiency, this aspect should be applied early on in the development of the PP, according to climatic conditions (general, by climatic area, and particular to the site) and to the land use distribution (that will influence transportation modes within the community). 


\subsubsection{Building}

The integrated methodology develops several hypotheses to model different building typologies, considering the previously identified aspects (Table 1): building typology (volume), parcel (form, dimension, and orientation), distance between buildings, percentage of glazing, and shading elements. The heating and cooling demand of the alternatives is modelled using the software tool EnergyPlus. The modelling exercise first takes each aspect separately (e.g. volume, glazing, shading elements) and then combines them, generating a set of building alternatives with different energy efficiency characteristics.

\subsubsection{Other urban elements: street network and open space network}

Among the different networks analysed, the north-south street network, used from the times of the Greek and the Roman (Cardus and Decumanus), enables the highest passive solar gain. Open spaces (squares, courtyards, pocket parks, and parks) affect Temperature and Humidity, directly affecting in the comfort of the surrounding buildings. In this sense, the permeability, albedo, conductivity, and emissivity of the materials that make up these spaces (e.g. water, vegetation, and paving) is highly relevant.

\subsubsection{Building solutions}

The methodology explores different building solutions applicable to buildings and other urban elements (streets and open spaces), creating a palette of sitespecific solutions and materials to aid the designer in the selection of optimal ones for the selected case study. These are grouped by façade, roof, ground floor slab, glazing, and vegetation (Table 1).

\subsection{Evaluation and selection of optimal solutions for energy demand}

Considering the variety of solutions from the urban to the building detail scales, an evaluation process enables the selection of the best alternatives to optimize the energy demand of the case study. According to the parameters previously defined, the methodology defines a set of 31 indicators (Table 2). The table presents a summary of the indicators developed for the case study with assigned values. These originate from best practices and from optimal results as of energy simulations developed specifically for the case study conditions through the software tool Energy Plus.

Applied to the case study, the proposed concept plan uses passive design to maximize solar gain in open spaces and buildings, with a large amount of southfacing buildings and large open spaces running from North to South. Buildings allow natural crossed ventilation and lighting, and compact building forms limit energy demand. In all, the new mixed-use community includes 2,495 dwellings $\left(341,078 \mathrm{~m}^{2}\right)$, office $\left(73,094 \mathrm{~m}^{2}\right)$, amenities $\left(38,220 \mathrm{~m}^{2}\right)$, and open spaces $\left(242,044 \mathrm{~m}^{2}\right)$. Table 3 provides a few of the values resulting from the concept plan (case study) and compares them to the methodology indicator values.

The resulting community-wide energy demand is calculated through the software tool CEEM-U (Economic and Energy Calculus for Urban Microgrids). The tool, developed by Labein Tecnalia, is oriented to the design and planning of 
Table 2: $\quad$ Summary of indicators.

\begin{tabular}{|c|c|c|}
\hline $\begin{array}{l}\text { Urban } \\
\text { planning }\end{array}$ & $\begin{array}{l}\text { 1. Percentage of economic activities, amenities and } \\
\text { services } \\
\text { 2. Proximity to daily activities } \\
\text { 3. Housing density (gross) } \\
\text { 4. \% knowledge-dense activities } \\
\text { 5. Accessibility to amenities and basic services } \\
\text { 6. Minimum reserve for social housing } \\
\text { 7. Percentage of green open space (including green roofs) }\end{array}$ & $\begin{array}{l}>20 \% \\
>10 \% \\
>50 \text { uph } \\
>10 \% \\
100 \% \\
30-50 \% \\
50 \%\end{array}$ \\
\hline Building & $\begin{array}{l}\text { 8. Optimal building typologies } \\
\text { 9. Massing factor } \\
\text { 10. Orientation of longitudinal façades } \\
\text { 11. Optimal parcel shape } \\
\text { 12. Distance / height ratio } \\
\text { 13. Percentage of windows in façade }\end{array}$ & $\begin{array}{c}\text { Building width } 8-12 \mathrm{~m} \\
0.24-0.34 \\
\text { North -South } \\
\text { rectangular } \\
1.5 \\
\text { Housing: S } 50 \%, \mathrm{~N} \\
5 \% \text {, E-W } 10 \% \\
\text { Offices: S } 50 \%, \mathrm{~N} \\
20 \%, \mathrm{E}-\mathrm{W} 30 \% \\
\text { S, E and W } \\
0.5-1.5\end{array}$ \\
\hline $\begin{array}{l}\text { Other } \\
\text { urban } \\
\text { elements }\end{array}$ & $\begin{array}{l}\text { 16. Street network assigned for private and public vehicles } \\
\text { 17. Street network assigned for pedestrians and other } \\
\text { public space uses } \\
\text { 18. Percentage of closed condominiums } \\
\text { 19. Trees in the street network } \\
\text { 20. Accessibility to on-street public transit stops ( } 300 \mathrm{~m}) \\
\text { 21. Accessibility to bicycle network }(300 \mathrm{~m}) \\
\text { 22. Accessibility and provision for private vehicle parking } \\
\text { 23. Provision for bicycle parking } \\
\text { 24. Accessibility for people with reduced mobility } \\
\text { 25. Permeability index } \\
\text { 26. Accessibility to green open space }\end{array}$ & $\begin{array}{c}<25 \% \\
>75 \% \\
0 \% \\
1 \text { tree } / 20 \mathrm{~m}^{2} \\
100 \% \\
100 \% \\
300 \mathrm{~m}, 1 \mathrm{spot} / \mathrm{du} \\
2 \text { spots } / \text { dwelling unit } \\
\text { Sidewalks }>2.5 \mathrm{~m} \\
>0.3 \\
>1000 \mathrm{~m}^{2},<200 \mathrm{~m} \\
>5000 \mathrm{~m}^{2},<750 \mathrm{~m} \\
>1 \mathrm{Ha},<2 \mathrm{~km} \\
>10 \mathrm{Ha}<4 \mathrm{~km}\end{array}$ \\
\hline $\begin{array}{l}\text { Building } \\
\text { solutions }\end{array}$ & $\begin{array}{l}\text { 27.Inertial mass / insulation ratio in façades } \\
\text { 28. Inertial mass / insulation ratio in roofs } \\
\text { 29. Insulation in ground floor slab } \\
\text { 30. Glazing type according to orientation }\end{array}$ & $\begin{array}{c}\text { Housing: high, } \\
\text { Offices: CTE } \\
\text { Regulation (CTE) } \\
\text { Regulation (CTE) } \\
\text { Multiple: all } \\
\text { Absorbent: S, E, W } \\
\text { Reflecting: E, W } \\
\text { Low emissivity: all } \\
\text { Radiation-selective } \\
\text { (e.g. electrochromic): } \\
\text { all } \\
\text { Transmittance: } \\
\text { housing } 30 \%<\text { CTE, } \\
\text { offices } 20 \%<\text { CTE, } \\
\text { Solar factor: offices } \\
15 \%<\text { CTE, housing } \\
<2 \times \text { value in offices }\end{array}$ \\
\hline
\end{tabular}


Table 3: Comparison of methodology indicators and case study values.

\begin{tabular}{|c|c|c|}
\hline Indicators & Methodology & Concept plan \\
\hline $\begin{array}{l}\text { Urban planning } \\
\text { 1. Percentage of economic activities, amenities and } \\
\text { services } \\
\text { 2. Proximity to daily activities } \\
\text { 3. Housing density (gross) } \\
\text { 4. \% knowledge-dense activities } \\
\text { 6. Minimum reserve for social housing } \\
\text { 7. Percentage of green open space (including green roofs) }\end{array}$ & $\begin{array}{c}>20 \% \\
>10 \% \\
>50 \text { uph } \\
>10 \% \\
30-50 \% \\
50 \% \\
\end{array}$ & $\begin{array}{c}11 \% \\
54 \text { uph } \\
21 \% \\
40 \% \\
52 \% \\
\end{array}$ \\
\hline $\begin{array}{l}\text { Building } \\
\text { 8. Optimal building typologies } \\
\text { 9. Massing factor } \\
\text { 10. Orientation of longitudinal façades }\end{array}$ & $\begin{array}{l}\text { Building width 8- } \\
12 \mathrm{~m} \\
0.24-0.34 \\
\text { North -South }\end{array}$ & $\left|\begin{array}{c}91 \% \text { of buildings } \\
\text { within this range of } \\
\text { width } \\
63 \% \text { of buildings } \\
\text { within this range } \\
87 \% \text { of buildings }\end{array}\right|$ \\
\hline $\begin{array}{l}\text { Other urban elements } \\
\text { 17. Street network assigned for pedestrians and other } \\
\text { public space uses } \\
\text { 22. Accessibility and provision for private vehicle parking } \\
\text { 23. Provision for bicycle parking } \\
\text { 25. Permeability index }\end{array}$ & $\begin{array}{c}>75 \% \\
300 \mathrm{~m}, 1 \mathrm{spot} / \mathrm{du} \\
2 \text { spots } / \mathrm{du} \\
>0.3 \\
\end{array}$ & \begin{tabular}{|c|}
$86 \%$ \\
$300 \mathrm{~m}, 2.2$ spots $/ \mathrm{du}$ \\
2 spots $/ \mathrm{du}$ \\
0.39 \\
\end{tabular} \\
\hline
\end{tabular}

urban microgrids taking the planning parameters of the case study. The tool is validated with EnergyPlus (Perea et al. [7]). The application of the methodology shows an important reduction in the community's overall energy demand. Comparing the case study with the methodology applied (proposed concept plan) to the preliminary concept plan that served as a basis for the case study, the reduction is $45.5 \%$ in the heating demand $\left(\mathrm{kwh} / \mathrm{m}^{2}\right.$ year) and $6.7 \%$ in the cooling demand. This results in a global contribution to the heating and cooling of $21.6 \%$.

\section{Optimization of the community's energy generation}

\subsection{On-site energy generation}

In terms of energy generation, the proposed methodology establishes two phases. The first consists of the dimensioning of the energy generating facilities for the whole case study site. Energy generation includes electric photovoltaic $\left(10.000 \mathrm{~m}^{2}\right.$ of PV panels), thermal solar panels $\left(1.000 \mathrm{~m}^{2}\right)$, and low temperature geothermal (375kW for 25 buildings). The proposal also includes a CHP, which simultaneously generates electric and thermal energy, burning different types of resources: natural gas and biomass or biogas (these two considered renewables). In all, the new community proposed for the case study is estimated to generate $40 \%$ of its energy through renewable energy (Table 4 ).

The second phase looks at establishing separate zones within the site for energy supply. The CHP and most of the PV panels are grouped in a microgrid in the South of the site, where most of the commercial and office buildings are 
located. This accomplishes the regulation requirements by far, places together the generation sources subject to be operated by the microgrid, reduces the heating loss of the surrounding buildings, locates the sources close to the electric infrastructure (substation), and leaves the buildings' rooftop area free for the residents leisure use. In the rest of the site (not operated by the microgrid), other generation sources (solar thermal and geothermal) operate on an individual basis through distributed or dispersed renewable generation.

Table 4: Renewable energy generation.

\begin{tabular}{|cl|}
\hline Electric generation & \\
\hline Photovoltaic & $12 \%$ of electric demand \\
CHP & $22 \%$ of electric demand \\
\hline Thermal generation & \\
\hline Geothermal & $4 \%$ of thermal demand $(7 \%$ of heating demand) \\
Solar thermal & $9 \%$ of thermal demand $(43 \%$ hot water demand) \\
CHP & $31 \%$ of thermal demand \\
\hline Total renewable generation & $\mathbf{4 0 \%}$ of total energy demand (electric + thermal) \\
\hline
\end{tabular}

\subsection{Cost-effective analysis}

Pursuing the practical applicability of the solutions proposed, the methodology develops a cost-effective analysis of the energy generation strategy. This considers investment and maintenance costs, energy prices [9-11], benefits from energy sale, return periods, etc. and is based in economic criteria (annual net value for 20 years) as well as technical criteria (equivalent technical output of the high efficiency energy generation sources [12]). The cost-effective analysis of phase one (energy generation for the whole site) considers the following parameters: community-wide predicted loads, climate, technology and resource costs, incentives, energy efficiency, and existing regulations. The analysis concludes that if natural gas is the raw material, the CHP's optimal power should be less than $300 \mathrm{~kW}$. If the raw material is forest biomass, the power should be less than 3MW. Similarly, current incentives in Spain economically encourage the sale of electric energy produced through biomass versus that produced through natural gas. Besides, efficiency requisites in the equipment are lower, $59 \%$ of equivalent electric output in natural gas versus $30 \%$ in biomass. Last, if the raw material is biogas from pellets, the nominal power should be less than $600 \mathrm{~kW}$.

Each of the separate zones within the site (phase two) includes its own costeffective analysis. In the area to the south, where the microgrid is located, the investment return period is estimated as 20 years (without extra microgrid cost) or 30 years (with extra microgrid cost). In the rest of the site, the estimated return period is 20 years. Although the periods are relatively long, it is worth mentioning that no additional financing has been considered other than the existing incentives before mentioned.

The microgrid should be operated by an ESCo (Energy Service Company), which develops a detailed analysis of the facilities and designs an energy efficiency solution, installs the required elements, and maintains the facilities 
during the investment return period. A great percentage of the savings in the energy bill is normally used to pay off the investment, in periods of 5 to 20 years. If the project does not meet the benefits initially estimated, the ESCo assumes the losses.

\section{Conclusions}

This paper has defined a methodology that integrates energy efficiency concepts into the urban design and planning process. Its application to a case study puts forward the following conclusions, valid for a wide-reaching design of energy efficient urban communities. The first is the importance of integrating energy efficiency concepts throughout the different stages and scales of a community's planning, design, and building process. This involves developing and defining general and site-specific parameters, creating a set of alternatives to first reduce energy demand and then generate supply, and, finally, evaluating and selecting the most suitable alternatives. The second key conclusion emphasizes the development of decision support tools to enable the evaluation of different energy efficiency alternatives. These tools, such as energy modelling for buildings within the urban fabric and energy generation and storage planning, consider the maximization of energy efficiency within an economically viable context. This makes possible the practical implementation of the solutions proposed.

This integrated methodology benefits institutions, developers, and energy facility companies. But most importantly, it benefits the end users - the communities - contributing to better quality and environmentally responsible buildings and urban environments.

\section{References}

[1] Eurostat, "Energy Yearly Statistics 2006", Eurostat Statistical Books, 2008 Edition, page 149, 2008

[2] Eurostat, "Energy Yearly Statistics 2006", Eurostat Statistical Books, 2008 Edition, page 9, 2008

[3] Código Técnico de la Edificación (Spanish Building Code), "Documento Básico HE Ahorro de Energía" (Basic Document for Energy Saving), www.codigotecnico.org

[4] IDAE - Instituto para la Diversificación y el Ahorro de la Energía (Institute for Diversification and Saving of Energy), "2008-2012 Action Plan under Spain's Energy Saving and Efficiency Strategy (E4)", Spanish Ministry of Industry, Tourism and Commerce, 2007

[5] European Parliament and Council, "Directive 2006/32/EC on energy enduse efficiency and energy services", 2006

[6] Spanish Ministry of Industry, Tourism and Commerce, "Real Decreto 661/2007" that regulates the activity of electric energy production, 2007 
[7] E. Perea, R. Rodríguez, E. Turienzo, C. Madina, A. Romero, E. Zabala, "Microgrids, a sustainable solution for an integral energy supply to ecocities", DYNA, Volume 83, Number 9, pages 550-560, 2008

[8] E. Perea (Coordinator), "La microrred: una alternativa de futuro para un suministro energético integral", TECNALIA Edition, ISBN 978-84-6127972-2, 2008

[9] Spanish Ministry of Industry, Tourism and Commerce, "Orden ITC/3860/2007" that revises energy rates, and "Orden ITC/3861/2007 that revises energy rates for natural gas, 2007

[10] Spanish Ministry of Industry, Tourism and Commerce, "Orden ITC/1857/2008" that revises energy rates, 2008

[11] Spanish Ministry of Industry, Tourism and Commerce, "Real Decreto $222 / 2008$ " that establishes the retributive regime for the activity of energy distribution, and "Real Decreto 222/2008" on the retribution of electric energy production through solar photovoltaic technology, 2008

[12] The Commission Of The European Communities, "Commission Decision of 21 December 2006 establishing harmonised efficiency reference values for separate production of electricity and heat in application of Directive 2004/8/EC of the European Parliament and of the Council", Official Journal of the European Union, 2007 